\title{
Paroxysmal Nocturnal Hemoglobinuria with Glucose-6-Phosphate Dehydrogenase Deficiency: A Case Report and Review of the Literature
}

\author{
Mahmoud S. Eisa ${ }^{a} \quad$ Shehab F. Mohamed $^{\mathrm{b}}$ Firyal Ibrahim $^{\mathrm{b}}$ \\ Khalid Shariff ${ }^{a}$ Nagham Sadik $^{a}$ Abdulqadir Nashwan $^{b}$ \\ Mohamed A. Yassin ${ }^{b}$ \\ anternal Medicine Department, Hamad General Hospital, Hamad Medical Corporation, \\ Doha, Qatar; ${ }^{b}$ Hematology Department, National Center for Cancer Care and Research, \\ Hamad Medical Corporation, Doha, Qatar
}

\section{Keywords}

Paroxysmal nocturnal hemoglobinuria - Eculizumab - G6PD

\begin{abstract}
In this study, we are describing a female patient with paroxysmal nocturnal hemoglobinuria $(\mathrm{PNH})$ and glucose-6-phosphate dehydrogenase (G6PD) deficiency. Both diseases are known to cause hemolytic anemia that mediates the hemolysis of RBCs through several mechanisms. In PNH the hemolysis is mediated through complement activation and oxidative stress. G6PD enzyme is crucial in preventing damage to cellular structures caused by oxygen-free radicles. In G6PD deficiency the hemolysis is mediated through the oxidative stress created by oxygen-free radicles. Since both diseases mediate hemolysis through the oxidative stress, we hypothesize that both conditions have facilitated an effect on each other and this will reflect on the response to treatment, and this response to treatment
\end{abstract}




\section{Case Reports in Oncology}

Case Rep Oncol 2019;12:838-844

DOI: $10.1159 / 000503817$

(c) 2019 The Author(s). Published by S. Karger AG, Base www.karger.com/cro

Eisa et al.: Paroxysmal Nocturnal Hemoglobinuria with Glucose-6-Phosphate

Dehydrogenase Deficiency: A Case Report and Review of the Literature

could vary based on whether the two mutations occurred in the same gene or in two different $\mathrm{X}$ chromosomes. Having diagnosed $\mathrm{PNH}$, the management is very expensive and not all the patients can afford it, especially our patient who is a maid by occupation. So, the real challenge in our case is to monitor her in subsequent visits and to plan the treatment keeping in mind her financial status.

(c) 2019 The Author(s)

Published by S. Karger AG, Basel

\section{Introduction}

Paroxysmal nocturnal hemoglobinuria (PNH) is a clonal disorder caused by an acquired mutation in the phosphatidylinositol glycan anchor (PIGA) gene of hematopoietic stem cells. The PIGA gene located on the X chromosome encodes a protein that is essential for the formation of the glycosylphosphatidylinositol (GPI) anchor for membrane proteins. Mutations in PIGA result in loss of all GPI-anchored proteins, including CD55 and CD59 which are GPI-anchored type I cell surface proteins, that inhibit the formation of the C3 convertases and prevent the terminal polymerization of the membrane attack complex, respectively. As a consequence of losing CD55 and CD59 cells are susceptible to complement activation, leading to ongoing intravascular hemolysis of red blood cells (RBCs) [1].

Another mechanism that mediates the $\mathrm{PNH}$-induced hemolysis is the oxidative stress as the CD55- and CD59-negative cells were found to have a higher level of reactive oxygen species (ROS) than CD55- and CD59-positive cells and their oxidative status will increase more with complement activation [2].

In PNH, the non-PNH blood cells are often reduced in numbers, suggesting that, although qualitatively normal, they are produced by failing bone marrow. Indeed, PNH may arise in a patient who previously had severe bone marrow failure, or aplastic anemia (AA), and sometimes a patient with overt PNH evolves to AA [3].

PNH usually presents with signs and symptoms related to RBC hemolysis that include anemia, RBC lyses, and/or findings caused indirectly by hemoglobin release, such as smooth muscle dystonia, pulmonary hypertension, renal insufficiency, and hypercoagulability. In general, the degree of hemolysis correlates with the size of the erythrocyte PNH clone [4].

Glucose-6-phosphate dehydrogenase (G6PD) deficiency is the most prevalent enzyme deficiency [5]. It is an X-linked disorder. As a result, males who inherit a G6PD mutation are hemizygous for the defect; all of their RBCs are affected. Females who inherit G6PD mutations usually are heterozygous and usually have a milder form of anemia compared to men. Heterozygote females have two populations of cells, the cells that express the abnormal allele are G6PD deficient and are vulnerable to hemolysis. The presence of anemia will vary depending on the severity of deficiency in the affected cells and the percentage of expression of the abnormal allele in RBCs [6].

Homozygosity or compound heterozygosity for an abnormal G6PD gene is rare and these females are as severely affected as males.

The G6PD enzyme is part of the pentose monophosphate shunt. The pentose monophosphate shunt is the only source for NADPH in RBCs. NADPH is crucial in preventing damage to cellular structures caused by oxygen-free radicles. It does this by keeping glutathione in the 


\section{Case Reports in Oncology}

Case Rep Oncol 2019;12:838-844

DOI: $10.1159 / 000503817$

2019 The Author(s). Published by S. Karger AG, Basel www.karger.com/cro

Eisa et al.: Paroxysmal Nocturnal Hemoglobinuria with Glucose-6-Phosphate Dehydrogenase Deficiency: A Case Report and Review of the Literature

reduced form. Reduced glutathione can convert hydrogen peroxide to water and prevent damage to cellular structures, particularly the cell wall of RBCs [6].

Unlike other cells; in RBCs, the pentose monophosphate shunt is the only source for NADPH. Thus, RBCs are more susceptible to oxidative stresses than other cells. In case of G6PD deficiency, RBCs will be vulnerable to oxidative stresses that can result in intravascular hemolysis [7].

The combination of PNH and G6PD is very rare. Here we report the case of a young Filipina who was diagnosed with both diseases, PNH and G6PD.

\section{Case Report}

A 31-year-old Filipina was admitted to our institute in December 2016 with the chief complaints of red-colored urine and yellowish discoloration of eyes. She also had episodes of dizziness, headache and exertional shortness of breath.

Prior to this, in December 2014, she had generalized swelling of her body and hematuria following an upper respiratory tract infection which required two sessions of hemodialysis (renal function test not known). The patient refused to go for kidney biopsy, so the nephrology team decided to start her on prednisolone $35 \mathrm{mg}$ and tapered gradually to $5 \mathrm{mg}$ as case of nephrotic syndrome continued on prednisolone $5 \mathrm{mg}$ till August 2016. Later on, she agreed to proceed with kidney biopsy that was done in the Philippines in August 2016, and the biopsy showed 3/24 glomerulosclerosis, no endocapillary or extracapillary proliferation. IgM 1+ staining was present with diffuse granular mesangial and segmental glomerular basement membrane and mild interstitial fibrosis and tubular atrophy. She was restarted on prednisolone $40 \mathrm{mg}$ along with enalapril which she continued to take till 2 weeks prior to her presentation.

On presentation, she was found to have marked anemia $\mathrm{Hb} 6.9 \mathrm{~g} / \mathrm{dL}(13-17 \mathrm{~g} / \mathrm{dL})$ with high MCV $109 \mathrm{fL}$ (83-101 fL), MCH $34 \mathrm{pg}$ (27-32 pg), and a high reticulocyte percentile of 23\% (0.5-2.5\%). Her peripheral smear showed a picture suggestive of hemolysis. However, her renal function was normal. The patient was discharged and planned to follow the autoimmune workup as an outpatient. Immunology and viral serology workup all came back negative.

She presented again after 1 year with the same complaints and was found to have marked anemia, with her peripheral smear showing a picture consistent with hemolysis again. The direct anti-globulin antibody test was negative and the patient subsequently received blood transfusions.

She had hemolysis as evidenced by raised LDH 2,165 U/L (125-220 U/L), low haptoglobin $<4 \mathrm{mg} / \mathrm{dL}$ (35-250 mg/dL), and raised bilirubin $37 \mu \mathrm{mol} / \mathrm{L}(3.4-20.5 \mu \mathrm{mol} / \mathrm{L})$. In the absence of a positive DAT test, this made us suspect PNH. To confirm the diagnosis, we performed peripheral blood flow cytometry that revealed a large (PNH) clone within the red cells (69.6\%), granulocytes (99\%), and monocytes (98\%). Bone marrow aspirate and biopsy were done subsequently. On October 1, 2017, bone marrow aspirate and biopsy confirmed the diagnosis of PNH both morphologically and by immunophenotypic markers, bone marrow cellularity $40-55 \%$ with trilineage hematopoiesis and erythroid predominance, and mildly reduced megakaryocyte. Normal karyotype 46XX. 
The hemolysis workup at the same time showed a G6DP level of $71.7 \mathrm{U} / 10^{12} \mathrm{RBCs}$ (245$500 \mathrm{U} / 10^{12} \mathrm{RBCs}$ ). Eculizumab has been requested for the patient, but meanwhile she is treated with intermittent blood transfusion. Since the time of diagnosis, the patient requires around 5 blood transfusions per year (Fig. 1).

\section{Discussion}

To our knowledge this is the third published report of the association between PNH and G6PD $[10,11]$.

PNH is a rare acquired hematopoietic stem cell disorder. Studies showed that the prevalence of $\mathrm{PNH}$ is in the range of 1-10 cases per million population, although this may be an underestimation as a subset of patients are likely to remain undiagnosed [8]. Even though $\mathrm{PNH}$ is caused by a mutation of a gene on the $\mathrm{X}$ chromosome, its incidence is equal in both sexes [9].

The treatment of choice for PNH is eculizumab. Eculizumab is a monoclonal antibody against complement protein 5 , as a result eculizumab blocks the formation of the membrane attack complex [1]. Having diagnosed PNH, the management is very expensive and not all patients can afford it, especially our patient who is a maid by occupation. So, the real challenge in our case is to monitor her in subsequent visits and plan the treatment keeping in mind her financial status.

The association between PNH and G6PD is very rare, on reviewing literature only 2 cases reported (Table 1) [10,11].

This association was first studied in 1970 when G6PD was used to prove the clonal nature of PNH through studying the correlation of red cell hemolysis with G-6-PD type in female G-6PD mosaics with PNH [12].

PNH is an X-linked disease and so is G6DP, so we suggest and hypothesize that both conditions have a facilitating effect on each other.

In both diseases, it is thought that the ROS plays an important role in the disease pathogenesis; this role will be more obvious in case of combined diseases. In a study where complement-mediated direct RBCs hemolysis was prevented by the usage of C5 blockers, complement activation result in a high level of oxidative stress which PNH G6PD deficient RBCs are unable to cope with [11].

In G6PD heterozygote female are usually asymptomatic except in rare condition but in case of combined G6PD and PNH in vivo and in vitro studies showed increase of ROS in RBCs that made the RBCs liable to hemolysis. In case of combined G6PD and PNH, a high level of ROS is found in both the PNH cells and the non-PNH cells, which is not the case with PNH alone with no G6PD deficiency, where high ROS is only found in the PNH cells [11].

The difference in response to eculizumab seen in those patients could be attributed to a unique interaction between the acquired PNH abnormality and the inherited G6PD deficiency. If the PNH mutation occurred in the same chromosome carrying the mutant G6PD gene, this will result in more severe disease and the response to eculizumab will not be optimal as in the Sardinia case [11]. On the other hand, if the PNH mutation has occurred in the other chromosome that is carrying the wild G6PD, this will result in optimal response to eculizumab as in the other case. 
Based on the comparison between the two previous cases, the difference in response to treatment results probably from whether mutations in PIGA would have taken place on the chromosome carrying the G6PD mutant gene or not.

Another interesting finding is that according to our literature review, all previous 3 cases, in addition to our case, were female.

\section{Conclusion}

We have described a case of PNH coexisting with G6PD. Although rare; it has pharmacogenetic implications. Further studies are required to robustly support this association.

\section{Statement of Ethics}

Ethical approval for this study was obtained from Medical Research Center At Hamad Medical Corporation (ABHATH) ID;MRC-04-18-211.

\section{Disclosure Statement}

The authors have no conflict of interest to declare.

\section{Funding Sources}

The publication of this article was funded by the Qatar National Library (QNL).

\section{References}

1 Brodsky RA. Paroxysmal nocturnal hemoglobinuria. Blood. 2014 Oct;124(18):2804-11.

2 Amer J, Zelig 0, Fibach E. Oxidative status of red blood cells, neutrophils, and platelets in paroxysmal nocturnal hemoglobinuria. Exp Hematol. 2008 Apr;36(4):369-77.

3 Pathare AV, Mohanty D. Paroxysmal nocturnal haemoglobinuria: the current scenario. J Postgrad Med. 1997 Jan-Mar;43(1):26-8.

4 Clinical manifestations and diagnosis of paroxysmal nocturnal hemoglobinuria - UpToDate. Available from: https://www.uptodate.com/contents/clinical-manifestations-and-diagnosis-of-paroxysmal-nocturnalhemoglobinuria?search=pnh\&source=search_result\&selectedTitle=1 73\&usage_type=default\&display_rank $=1$ [accessed 14 Jun 2019].

5 Nkhoma ET, Poole C, Vannappagari V, Hall SA, Beutler E. The global prevalence of glucose-6-phosphate dehydrogenase deficiency: a systematic review and meta-analysis. Blood Cells Mol Dis. 2009 MayJun;42(3):267-78.

6 Richardson SR, O’Malley GF. Glucose 6 Phosphate Dehydrogenase (G6PD) Deficiency. Treasure Island (FL): StatPearls Publishing; 2019.

7 Glucose-6-Phosphate Dehydrogenase (G6PD) Deficiency: Practice Essentials, Pathophysiology, Etiology. https://emedicine.medscape.com/article/200390-overview\#a5. 
8 Schrezenmeier H, Muus P, Socié G, Szer J, Urbano-Ispizua A, Maciejewski JP, et al. Baseline characteristics and disease burden in patients in the International Paroxysmal Nocturnal Hemoglobinuria Registry. Haematologica. 2014 May;99(5):922-9.

9 Dacie JV, Lewis SM. Paroxysmal nocturnal haemoglobinuria: clinical manifestations, haematology, and nature of the disease. Ser Haematol. 1972;5(3):3-23.

10 Perdigones N, Morales M, Mason P, Bessler M. Case Report: Paroxysmal nocturnal hemoglobinuria in a woman heterozygous for G6PD A-. Version 2. F1000Res. 2014 Aug 13 [revised 2014 Oct 21];3:194.

11 Sica M, Pellecchia A, Berardi M, Gargiulo L, Olutogun TA, Caocci G, et al. Complement Activation in Paroxysmal Nocturnal Hemoglobinuria (PNH) Causes Oxidative Damage Which May Affect Response to Eculizumab. Blood. 2014;124(21):4397.

12 Hartmann RC, Arnold AB. Paroxysmal nocturnal hemoglobinuria (PNH) as a clonal disorder. Annu Rev Med. 1977;28(1):187-94.
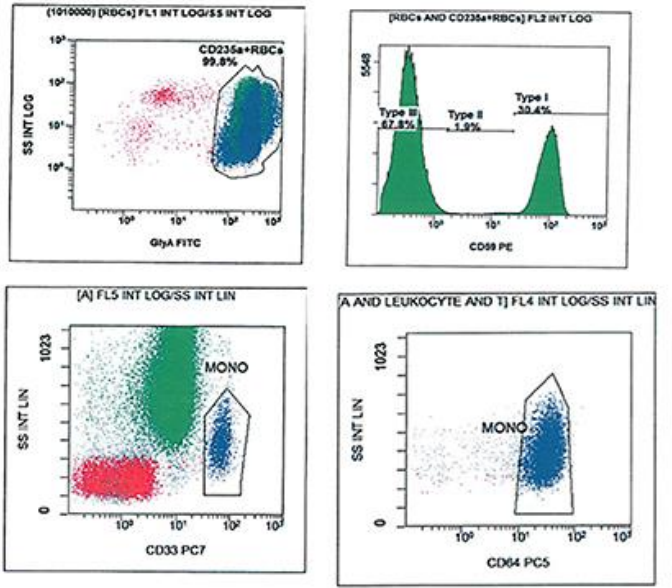
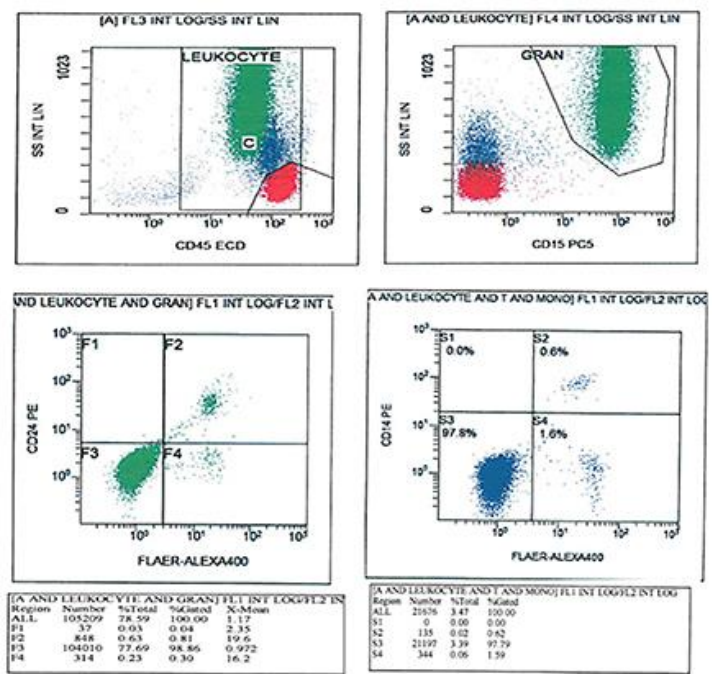

Fig. 1. Immunophenotypic analysis using gating antibodies glycophorin A (for red cells), CD45, CD15 (for granulocytes), CD33 and CD64 (for monocytes) and the GP-linked antibodies CD59, CD14, CD24 as well as fluorescent aerolysin (FLAER). A large (PNH) clone was found within the red cells (69.6\%), granulocytes (99\%), and monocytes (98\%). 


\section{Case Reports in Oncology}

\begin{tabular}{l|l} 
Case Rep Oncol 2019;12:838-844 \\
\hline DOI: 10.1159/000503817 & $\begin{array}{l}\text { (c) 2019 The Author(s). Published by S. Karger AG, Basel } \\
\text { www.karger.com/cro }\end{array}$ \\
\hline
\end{tabular}

Eisa et al.: Paroxysmal Nocturnal Hemoglobinuria with Glucose-6-Phosphate Dehydrogenase Deficiency: A Case Report and Review of the Literature

Table 1. Review of the reported cases of combined G6PD and PNH $[10,11]$

\begin{tabular}{llll}
\hline Case & Perdigones et al. [10], 2014 & Sica et al. [11], 2014 & Our case \\
\hline Age, years & 25 & 40 & 31 \\
Sex & Female & Female & Female \\
PNH/G6PD chromosome & Different & Same & 69 \\
PNH cells RBCs, \% & 65 & 20 & 95 \\
PNH cells granulocytes, \% & 94 & 95 & Lediterranean heterozygote \\
G6PD type & Heterozygous for G6PD A- & Low & No \\
Blood G6PD activity & Normal & Unknown & Transfusion \\
Thrombosis & Yes & Eculizumab & Partial response \\
Type of treatment & Eculizumab & 10 units & 5 units \\
Outcome & Complete response & & \\
Number of RBCs transfused per year & Not required & & \\
\hline
\end{tabular}

